http://dx.doi.org/10.31258/jta.v3i1.56-61

\title{
PENINGKATAN PENGETAHUAN BUDAYA MELAYU MELALUI PEMBELAJARAN BERBASIS KONTEKSTUAL (CTL) KELAS IV SDN 191 PEKANBARU
}

\author{
Elpri Darta Putra ${ }^{1) a)}$, Zaka Hadikusuma Ramadan" ${ }^{1)}$, Eva Astuti Mulyani ${ }^{2)}$ \\ ${ }^{1)}$ Program Studi PGSD FKIP Universitas Islam Riau \\ 2)Pendidikan Guru Sekolah Dasar FKIP Universitas Riau \\ a)elpri.dp@edu.uir.ac.id
}

\begin{abstract}
This research aims to describe to enhancement malav cultural knowedae of students Elementary School in Pekanbaru. The research was conducted at SDN 191 Pekanbaru City with the focus of the object of the research werw the students of class VI. The desian of this research was PTK (Classroom Action Research). The initial data of students was obtained namely 66.38 and in the first cycle 72.75 increased by a difference of 6.37 units. While the average student learning outcomes in the first cycle of 72.75 and in the second cvcle of 78.81 has increased by a difference of 6.06 units. The action is carried out by the teacher, by the teacher together with the students, or students under the quidance and direction of the teacher, with a view to improving and improving the quality of learning.
\end{abstract}

Keywords: Contextual Teaching Learning, Malay Culture

\section{PENDAHULUAN}

Pendidikan mampu mewujudkan suasana belajar dan proses pembelajaran dengan terencana untuk mengembangkan potensi peserta didik secara sadar dan aktif untuk memiliki kekuatan spiritual keagamaan, pengendalian diri, kepribadian, kecerdasan, akhlak mulia, serta keterampilan yang diperlukan dirinya dan masyarakat.Pendidikan meliputi pengajaran keahlian khusus, dan juga sesuatu yang tidak dapat dilihat tetapi lebih mendalam yaitu pemberian pengetahuan, pertimbangan dan kebijaksanaan.Meningkatkan pengetahuan budaya melayu, meningkatkan aktifitas belajar yang berkaitan dengan tunjuk ajar melayu, dan mengaplikasikan budaya melayu sebagai salah satu cara bertindak, bersikap dalam kehidupan sehari-hari.

Menurut Azhar (2018) secara universal pokok-pokok dalam tunjuk ajar melayu di Riau dari masa kemasa yang tergeser dan semakin sedikit baik pembaca penyimak maupun orang yang menjadikan tuntunan budaya melayu sebagai contoh dalam prilaku, bersikap dalam kehidupan sehari-hari

Masalah sosial di kalangan orang Melayu semakin membimbangkan. Kehidupan sosial orang Melayu, khususnya anak-anak hari ini begitu dipengaruhi oleh budaya asing. Orang Melayu seakan tidak mempunyai daya tahan dalam

E. D. Putra, Z. H. Ramadan, E.A. Mulyani, Peningkatan Pengetahuan Budaya Melayu Melalui Pembelajaran Berbasis Kontekstual (CTL) Kelas IV SDN 191 Pekanbaru 
menghadapi limpahan budaya asing yang semakin berkembang, Melalui kemajuan dalam bidang pendidikanlah orang Melayu mampu mendapat pengetahuan,sikap,keterampilan sesuai dengan ajaran budaya melayu dalam mempersiapkan diri dalam menyongsong kehidupan yang lebih baik. Namun persoalan utama ialah sistem pendidikan yang belum maksimal dalam mengarahkan siswa agar gemar, cinta terhadap kebudayaannya sendiri sesuai dengan harapkan.

Menurut Lie (2016) pendidik perlu menyusun dan melaksanakan kegiatan belajar mengajar berdasarkan beberapa pokok pemikiran sebagai berikut: (1) pengetahuan ditemukan, dibentuk, dan dikembangkan oleh siswa, (2) siswa membangun pengetahuan secara aktif, (3) pendidik perlu berusaha mengembangkan kompetensi dan kemampuan siswa, (4) pendidikan adalah interaksi pribadi di antara para siswa dan interaksi antara guru dan siswa.

Untuk membangun pengetahuan dan kompetensi siswa secara aktif di dalam proses belajar mengajar menurut Roestiyah (2000) guru harus memiliki strategi yang tepat agar siswa dapat belajar secara efektif dan efisien sesuai dengan tujuan yang diharapkan. Rendahnya kesadaran siswa tentang kebudayaan Melayu di sekolah dasar, merupakan bentuk kurangnya strategi dalam melaksanakan proses pembelajaran dalam mengajarkan pembelajaran budaya melayu dikelas.

\section{METODE PENELITIAN}

Desain penelitian ini adalah PTK (Penelitian Tindakan Kelas). Dimana desain ini terdapat dua kelompok, yaitu sebelum dan sesudah perlakuan. Penelitian ini dilaksanakan dikelas IVc SD Negeri 191 Pekanbaru. Subyek penelitian ini adalah siswa kelas IVc Dengan jumlah siswa 37 orang yang terdiri dari 19 laki-laki dan 18 perempuan. Secara garis besar penelitian kelas dilakukan melalui empat tahap yang lazim dilalui yaitu:

a. Perencanaan, yaitu menyusun RPP, membuat lembar kerja siswa dan merencanakan tes hasil belajar serta persiapan lembar pengamatan.

b. Pelaksanaan, yaitu kegiatan yang dilakukan oleh guru atau peneliti dalam upaya memperbaiki atau meningkatkan hasil belajar siswa.

c. Pengamatan, dilaksanakan oleh guru dengan menggunakan lembar pengamatan.

d. Refleksi, yaitu mengkaji,melihat dan mempertimbangkan atas hasil atau dampak tindakan

Penelitian ini terdiri dari 2 siklus yaitu siklus pertama dan siklus kedua. Pada siklus pertama dilakukan 2 kali pertemuan dengan 1 kali pertemuan ulangan harian, dan pada siklus kedua dilakukan 2 kali pertemuan dengan 1 kali pertemuan untuk ulangan harian. Dan desain penelitian ini dapat terlihat pada siklus dibawah ini:

E. D. Putra, Z. H. Ramadan, E.A. Mulyani, Peningkatan Pengetahuan Budaya Melayu Melalui Pembelajaran Berbasis Kontekstual (CTL) Kelas IV SDN 191 Pekanbaru 


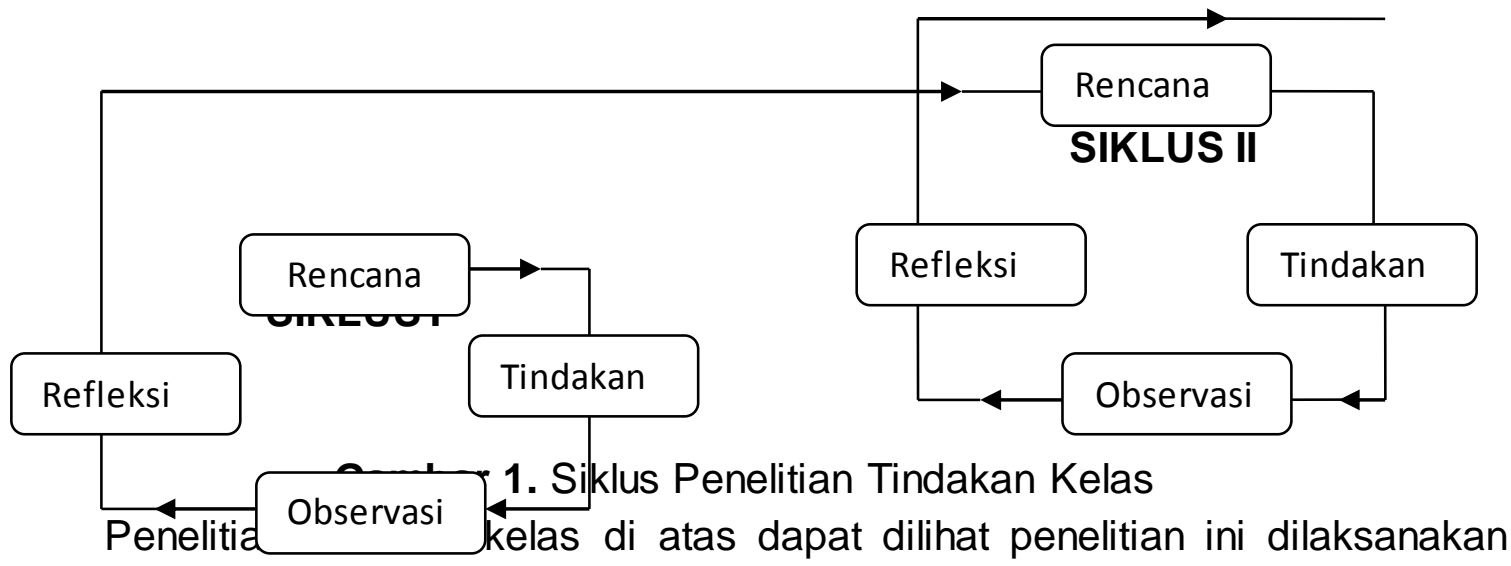

dua siklus yaitu siklus I dan siklus II. Setiap siklus dilakukan 2 kali pertemuan. Data yang dianalisis adalah yang diperoleh dari hasil pengamatan dan hasil belajar siswa dengan teknik statistik dekriptif. Teknik statistik deskriptif yaitu teknik analisis yang menggambarkan aktivitas guru dan siswa dalam proses pembelajaran serta hasil belajar yang secara individu dan klasikal.

\section{HASIL DAN PEMBAHASAN PENELITIAN}

Pertemuan pertama dilaksanakan selama dua jam pelajaran $(2 \times 35$ menit) dengan materi pakaian khas melayu. Penyajian materi dilaksanakan oleh peneliti di kelas IV dengan jumlah siswa 37 orang. Diawal pembelajaran guru membuka pelajaran dengan mengucapkan salam, menyiapkan siswa dan mengabsen kehadiran siswa. Selanjutnya guru mengajukan beberapa pertanyaan: Selanjutnya guru menyampaikan tujuan pembelajaran sekaligus memberikan penguatan serta memperlihatkan media. Kemudian guru meminta siswa untuk maju kedepan kelas untuk melakukan pengajaran mengenai materi yaitu Budaya Melayu, perwakilan siswa tersebut diminta untuk memberikan contoh bagaimana kebudayaaan dan pakaian khas melayu yang ada di Riau. Berdasarkan informasi dari guru dan dari demonstrasi tersebut,guru mengajukan pertanyaan kepada 3-4 orang siswa. Setelah melakukan tanya jawab, guru membentuk masyarakat belajar/ kelompok yang terdiri dari 4-5 orang siswa yang heterogen dan diberi LKS. Setelah setiap kelompok mendapatkan LKS dan mengerjakan LKS tersebut sesuai dengan langkah-langkah kegiatan yang telah disediakan. Pada saat mengerjakan LKS ini masih ada kelompok yang masih ragu-ragu dan bertanya dalam mengerjakannya. Hal ini dikarenakan siswa tidak terbiasa belajar secara berkelompok dan mengerjakan LKS. Setelah selesai mengerjakan LKS, guru meminta perwakilan tiga kelompok untuk mempresentasikan hasil kerja kelompoknya dan kelompok lain memberi saran dan tanggapan. Setelah selesai mempresentasikan hasil kerja kelompok, guru Memberikan pertanyaan atau meminta contoh-contoh lain mengenai meteri tentang bagaimana cara mereka menerapkan hasil pembelajaran di rumah maupun di lingkungan lainnya. Sejalan dengan pendapat

E. D. Putra, Z. H. Ramadan, E.A. Mulyani, Peningkatan Pengetahuan Budaya Melayu Melalui Pembelajaran Berbasis Kontekstual (CTL) Kelas IV SDN 191 Pekanbaru 
Richard (2010) menyebutkan pembelajaran CTL adalah model pembelajaran yang menekankan keterlibatan siswa secara keseluruhan proses untuk dapat mencari kegiatan belajar yang berhubungan dengan situasi kehidupan nyata, memotivasi siswa untuk menggali pengetahuan dan keterampilan yang diperoleh dalam kehidupan mereka. Setelah itu siswa diberi evaluasi yang dikerjakan pada buku latihan, soal evaluasi ini berbentuk essay terdiri dari lima soal.

Hasil refleksi siklus I yang dilakukan dua kali pertemuan diperoleh hasil sebagai berikut:

1. Pada saat pembelajaran berlangsung masih terdapat siswa yang belum aktif dalam menjawab dan mengajukan pertanyaan.

2. Pada saat mengerjakan LKS secara berkelompok masih terdapat siswa yang belum bisa bekerjasama. Karena pada saat itu sebagian anggota kelompok mengerjakan LKS dan anggota lain melakukan kegiatan yang lain dan seringkali ribut saat saat.mengerjakan LKS tersebut.

3. Pada saat mengikuti kegiatan pembelajaran masih terdapat siswa yang belum aktif,ribut dan melakukan kegiatan lain

Dari hasil refleksi siklus I, maka perencanaan perbaikan yang akan dilakukan pada siklus II adalah :

1. Memberikan motivasi kepada siswa agar mereka aktif mengajukan dan menjawab pertanyaan.

2. Membimbing siswa dalam menyelesaikan langkah-langkah yang ada pada LKS sehingga dapat bekerjasama dengan baik.

3. Memberikan motivasi dan membimbing siswa pada saat kegiatan pembelajaran dan kegiatan percobaan sehingga mereka antusias dan fokus mengikuti setiap kegiatan-kegiatan pembelajaran.

Tahap perencanaan pada siklus II pertemuan 2 untuk menerapkan model pembelajaran Kontekstual (Contextual Teaching and Learning) yang dipersiapkan sebelum tindakan yang dilakukan adalah mempersiapkan Silabus, membuat Rencana Pelaksanaan Pembelajaran (RPP) yang sesuai dengan silabus, membuat Lembar Kegiatan Siswa (LKS) yang sesuai dengan materi yang akan diajarkan yaitu cara menggunakan alat komunikasi yang benar, menyiapkan Lembar Latihan Evaluasi, membuat Lembar Aktivitas guru yang sesuai dengan model pembelajaran Kontekstual (Contextual Teaching and Learning), dan membuat Lembar Observasi siswa yang sesuai dengan penerapan model pembelajaran Kontekstual (Contextual Teaching and Learning).

Tahap pelaksanaan tindakan kelas berisikan penerapan model Kontekstual (Contextual Teaching and Learning) dalam proses pembelajaran di kelas. Pertemuan kedua dilaksanakan pada 2 jam pelajaran $(2 \times 35$ menit), dengan materi pelajaran menjelaskan Kebudayaan Melayu khususnya Melayu Riau. Penyajian materi dilaksanakan oleh peneliti di kelas IVc dengan jumlah siswa 37 orang (hadir semua).

E. D. Putra, Z. H. Ramadan, E.A. Mulyani, Peningkatan Pengetahuan Budaya Melayu Melalui Pembelajaran Berbasis Kontekstual (CTL) Kelas IV SDN 191 Pekanbaru 
Diawal pembelajaran guru membuka pelajaran dengan mengucapkan salam, menyiapkan siswa dan mengabsen kehadiran siswa. Setelah itu guru Guru memancing stimulus dengan memberikan pertanyaan-pertanyaan problematic tentang fenomena yang sering ditemui sehari-hari dengan mengaitkan konsep yang akan dibahas. Pernahkah kamu melihat Ombak Bono? Selanjutnya, guru mengajukan pertanyaan kepada siswa mengenai apakah Bono merupakan kebudayan melayu di Riau?. Setelah melakukan tanya jawab,sebelum siswa belajar dalam kelompok guru terlebih dahulu menyampaikan garis besar mengenai materi Kebudayaan Melayu Riau. Selanjutnya guru membentuk masyarakat belajar/ kelompok yang terdiri dari 4-5 orang siswa yang heterogen dan diberi LKS. Setiap kelompok mendapatkan LKS dan mengerjakan LKS tersebut. Pada tahap ini siswa mengerjakan LKS dengan semangat dan bekerjasama dengan baik dengan kelompoknya masing-masing.. Pada tahap mengerjakan LKS tidak ada lagi siswa yang bertanya. Setelah selesai mengerjakan LKS, guru meminta tiga kelompok untuk mempresentasikan hasil kerja kelompoknya dan kelompok lain memberi saran dan kritikan yang positif. Pada kegiatan ini, guru meminta siswa yang belum pernah mempresentasikan hasil kerja kelompoknya. Setelah selesai mempresentasikan hasil kerja kelompok, guru Memberikan pertanyaan atau meminta contoh-contoh lain mengenai meteri tentang bagaimana cara mereka menerapkan hasil pembelajaran di rumah maupun di lingkungan lainnya. selanjutnya siswa diberi evaluasi yang dikerjakan pada buku latihan, soal evaluasi ini berbentuk essay yang terdiri dari empat soal untuk mengetahui sejauh mana penguasaan siswa terhadap materi yang telah dipelajarinya.

Setelah siswa selesai mengerjakan soal evaluasi, guru melakukan refleksi dengan cara membahas bersama hasil diskusi kelompok yang sudah dipersentasikan, dari hasil pembahasan yang dilakukan secara bersama-sama, guru memberikan penilaian kepada siswa. Dari hasil kerja kelompok yang memperoleh nilai baik akan diberi predikat memuaskan dan mendapatkan reward. Sedangkan yang memperoleh nilai yang kurang baik, akan diberi predikat kurang memuaskan dan akan diberi hukuman yaitu diberi tugas untuk dikerjakan dirumah. Untuk hasil kerja individu, bagi yang mendapat nilai baik mendapat pujian, sedangkan yang mendapat nilai kurang baik, mendapat hukuman mengerjakan latihan dirumah. Sebagai tindak lanjut, siswa diminta untuk membaca buku dirumah tentang materi budaya Melayu Riau yang telah dipelajari.

\section{SIMPULAN}

1. Rata-rata hasil belajar data awal siswa diperoleh yaitu 66,38 dan pada siklus I 72,75 mengalami peningkatan dengan selisih 6,37 . Sedangkan rata-rata hasil belajar siswa pada siklus I 72,75 dan pada siklus II yaitu 78,81 mengalami peningkatan dengan selisih 6,06. Ketuntasan hasil belajar secara klasikal pada data awal yang diperoleh hanya 15 siswa $(40,54 \%)$ yang mancapai KKM, pada

E. D. Putra, Z. H. Ramadan, E.A. Mulyani, Peningkatan Pengetahuan Budaya Melayu Melalui Pembelajaran Berbasis Kontekstual (CTL) Kelas IV SDN 191 Pekanbaru 
siklus I hanya 26 siswa $(70,27 \%)$ yang mencapai KKM kemudian meningkat pada siklus II menjadi 31 siswa $(83,78 \%)$ yang mencapai KKM.

2. Peningkatan pengetahuan di atas ditunjang oleh:

a. Persentase aktivitas guru dalam melaksanakan pembelajaran pada siklus I pertemuan pertama yaitu $67,5 \%$ dalam kategori cukup dan pertemuan kedua yaitu $77,5 \%$ dalam kategori baik mengalami peningkatan dengan selisih $10 \%$. Pada siklus II pertemuan pertama yaitu $87,5 \%$ dalam kategori baik dan pertemuan kedua yaitu $92.5 \%$ dalam kategori sangat baik mengalami peingkatan dengan selisih $5 \%$. Sedangkan selisih antara pertemuan pertama siklus I yaitu 67,5\% hingga pertemuan kedua Siklus II yaitu 92,5\% adalah $25 \%$.

b. Persentase aktivitas belajar siswa pada siklus I pertemuan pertama yaitu $64,86 \%$ dalam kategori cukup dan pertemuan kedua yaitu 78,50\% dalam kategori bagus mengalami peningkatan dengan selisih 13,64\%. Pada siklus II pertemuan pertama yaitu $84,32 \%$ dalam kategori bagus dan pertemuan kedua yaitu $89,45 \%$ dalam kategori bagus mengalami peningkatan dengan selisih 5,13\%. Sedangkan persentase aktivitas belajar siswa antara pertemuan pertama siklus I yaitu $64,86 \%$ hingga pertemuan kedua siklus || yaitu $89,45 \%$ dengan selisih $24,59 \%$.

\section{DAFTAR PUSTAKA.}

Arikunto, S. (2009). Dasar-dasar pembelajaran. Bumi Aksara. Jakarta.

Agus, N. (2013). Panduan Aplikasi Teori-Teori Belajar Mengajar, Yogyakarta: Diva Press.

Azhar. (2018). Teori Kebudayaan Melayu. Pariwisata Riau

Dimyati, dkk. (2006). Belajar dan Pembelajaran. Rineka Cipta. Jakarta.

Hughes, J (2009). An Instruksional Model of Preparing Teachers for Fieldwork. International Journal of Teaching and Learning in Higher Education $v 21$ number 2 p252-257.

Roestiyah. (2000). Strategi Belajar Mengajar. Rineka Cipta. Jakarta.

Richard A, (2010). Contextual Teaching And Learning, International Journal of the Psychonomic Society1982, Vol. 20(6), 290-292.

Robert G. Berns. (2001). Contextual Teaching and Learning. Preparing Students for the New technology. journal of education research, 76(4):210-211.

Sagala. (2005). Konsep dan Makna Pembelajaran. Alfabeta. Bandung.

Sanjaya, W. (2009). Strategi Pembelajaran Berorientasi Standart Proses Pendidikan. Kencana. Jakarta.

Sudjana. (2005). Metoda Statistika. Tarsito. Bandung.

Suwardi. (2007). Kebudayaan Melayu. Pariwisata Riau. Pekanbaru.

Slavin, R.E. (2008). Cooperative Learning Teori, Riset dan Praktik. Nusa Media. Bandung.

Zulkarnain. (2013) Kebudyaan Melayu, Pariwisata Riau: Pekanbaru

E. D. Putra, Z. H. Ramadan, E.A. Mulyani, Peningkatan Pengetahuan Budaya Melayu Melalui Pembelajaran Berbasis Kontekstual (CTL) Kelas IV SDN 191 Pekanbaru 